\title{
Correlation of Prenatal and Postnatal MRI Findings in Schizencephaly
}

\author{
S.A. Nabavizadeh, D. Zarnow, L.T. Bilaniuk, E.S. Schwartz, R.A. Zimmerman, and A. Vossough
}

\begin{abstract}
BACKGROUND AND PURPOSE: Schizencephaly is a rare malformation of the brain characterized by a gray matter-lined defect extending from the pial surface to the lateral ventricles. The purpose of this study was to correlate imaging findings of schizencephaly and associated anomalies on fetal and postnatal MR imaging and assess possible changes that may occur from the prenatal-to-postnatal state.
\end{abstract}

MATERIALS AND METHODS: A retrospective review of subjects with schizencephaly who had both pre- and postnatal MR imaging was performed. Subject age, cleft type, number, location, and features of the defects and associated anomalies were recorded. Normalized dimensions of the defect and ipsilateral ventricle were measured and correlated to changes in the clefts between pre- and postnatal imaging.

RESULTS: Ten subjects with 18 clefts ( 8 bilateral) were included. Most defects (83\%) were open on prenatal MR imaging, but $47 \%$ of those were found to have subsequently closed on postnatal imaging. Evidence of prior hemorrhage was seen in $83 \%$. Prenatal MR imaging detected all cases of an absent septum pellucidum but detected a fraction of gross polymicrogyria and missed all cases of optic nerve hypoplasia. The normalized ipsilateral ventricular and inner and middle width dimensions of the defects were significantly decreased at postnatal imaging $(P<.05)$. The widths of the defects, ventricular width, and presence of hemorrhage were not predictors of closure of prenatally diagnosed open defects $(P>.05)$.

CONCLUSIONS: In our series, nearly half of prenatally open schizencephaly defects had closed on postnatal imaging. Prenatal MR imaging was only able to demonstrate some of the associated anomalies.

S chizencephaly is a rare malformation of the central nervous system characterized by a gray matter-lined defect extending from the pial surface to the lateral ventricles. The etiology of schizencephaly is poorly understood; however, it appears to be heterogeneous. ${ }^{1-3}$ The presence of gray matter lining the defects, distinguishing schizencephaly from porencephaly, is usually ascribed to the damage to the radial glial cell fibers or to the molecules that promote neuronal migration and timing during pregnancy. ${ }^{2,4}$ Despite early reports of the association of schizencephaly and mutations of the EMX2 homeobox gene, ${ }^{5}$ this association

Received September 26, 2013; accepted after revision November 19.

From the Department of Radiology, Children's Hospital of Philadelphia, Philadelphia, Pennsylvania; and Department of Radiology, University of Pennsylvania, Philadelphia, Pennsylvania.

Please address correspondence to Arastoo Vossough, PhD, MD, Department of Radiology, Children's Hospital of Philadelphia, 324 S 34th St, Wood 2115, Philadelphia, PA 19104; e-mail: vossough@email.chop.edu

Indicates article with supplemental on-line table.

http://dx.doi.org/10.3174/ajnr.A3872 has not been verified in further studies. ${ }^{6}$ The common pathophysiology of injury is frequently ascribed to a vascular disruption, hypoxia-ischemia, and/or prenatal infection at critical time points during neuronal development, ${ }^{1-3}$ though there are some reports favoring schizencephaly as a developmental disorder. ${ }^{7-9}$

Classically, schizencephaly has been divided into "closed" or "closed-lip" defects, in which the walls appose one another within the defect, and "open" or "open-lip" defects, in which CSF fills the defect all the way from the lateral ventricle to the overlying subarachnoid space. ${ }^{10}$ Open lesions have been further subclassified as small or large according to size of the defect. ${ }^{10}$ These classifications have prognostic significance because it has been shown that a small, unilateral closed defect without involvement of the motor cortex can be associated with seizures but otherwise normal development. ${ }^{10}$ The prognosis is poorer with open and bilateral defects. ${ }^{2,10,11}$ Associated anomalies, such as optic nerve hypoplasia, absence of the septum pellucidum, and other migrational abnormalities, will also adversely affect the prognosis. ${ }^{2,9,12,13}$

MR imaging was reported to prenatally diagnose schizencephaly as early as $1989 .{ }^{14}$ On the basis of the current literature, the 
imaging appearance of schizencephaly on fetal MR imaging is considered identical to that in postnatal MR imaging. ${ }^{2}$ The purpose of this study was to correlate imaging findings of schizencephaly and associated anomalies on fetal and postnatal MR imaging and to assess the possible changes that may occur from the prenatal-to-postnatal state on MR imaging.

\section{MATERIALS AND METHODS}

A retrospective review of fetal MRI at our institution was performed. A key word search of the PACS was done to find fetuses that were diagnosed with schizencephaly or porencephaly between 2000 and 2012. We included patients with the prenatal diagnosis of porencephaly in our primary search due to the potential difficulty of differentiating schizencephaly and porencephaly on prenatal MR imaging in some cases. Medical records were reviewed to determine which fetuses had postnatal brain MR imaging available to review. Medical records were also reviewed for subject sex and age at the time of prenatal and postnatal examinations. The study was performed with the approval of the institutional review board.

Retrospective search and chart review initially revealed 44 prenatal subjects. All patients had been referred from outside institutions for fetal MR imaging at our tertiary fetal diagnosis center. The MR imaging diagnosis among these patients included 23 with bilateral schizencephaly (52.2\%), 9 with unilateral schizencephaly (20.4\%), 8 with porencephaly (25\%), 1 with agenesis of the corpus callosum with an interhemispheric cyst (2.2\%), and 1 with transmantle cortical dysplasia (without heterotopia) confirmed postnatally (2.2\%). In 2 patients, the distinction between schizencephaly and porencephaly could not be made on the basis of the available prenatal imaging (4.4\%) and there was no postnatal follow-up. In the end, 10 subjects had both prenatal and postnatal MR imaging confirming schizencephaly and were, therefore, included in this study. The diagnosis of schizencephaly was further confirmed on postnatal MR imaging on the basis of the presence of a gray matter-lined defect extending from the brain surface to the ventricular system. The remaining fetal patients with a diagnosis of schizencephaly were not followed at our institution and were, therefore, excluded from this study. The outcome of the excluded subjects is not known to us.

\section{MR Imaging Protocol}

Prenatal MR imaging was performed on 1.5T magnets (Siemens, Erlangen, Germany). We used the following sequences: T2 HASTE in multiple orthogonal planes ( TR $=1100 \mathrm{~ms} ; 2$ different sequences with TEs of 78 and $64 \mathrm{~ms}$ each, respectively; FOV $=280$ $\mathrm{mm}^{2}$; matrix $=56 \times 192$; section thickness $\left.=3 \mathrm{~mm}\right)$ and 2 different echo-planar $\mathrm{T} 2^{*}$ sequences with different sensitivities to susceptibility (first with TR $=5290 \mathrm{~ms}, \mathrm{TE}=94 \mathrm{~ms}$; second with $\mathrm{TR}=4200 \mathrm{~ms}, \mathrm{TE}=42 \mathrm{~ms}$, generalized autocalibrating partially parallel acquisition 2; and both with flip angle $=90^{\circ}, \mathrm{FOV}=280$ $\mathrm{mm}^{2}$, matrix $=256 \times 256$, section thickness $\left.=3 \mathrm{~mm}\right)$. Also T1 FLASH $\left(\mathrm{TR}=202 \mathrm{~ms}, \mathrm{TE}=4.76 \mathrm{~ms}, \mathrm{FOV}=280 \mathrm{~mm}^{2}\right.$, flip angle $=60^{\circ}$, matrix $=256 \times 166$, section thickness $=4 \mathrm{~mm}$ ) was available in patients who were imaged after 26 weeks' gestational age.

Postnatal MR imaging was performed on $1.5 \mathrm{~T}$ or $3 \mathrm{~T}$ magnets

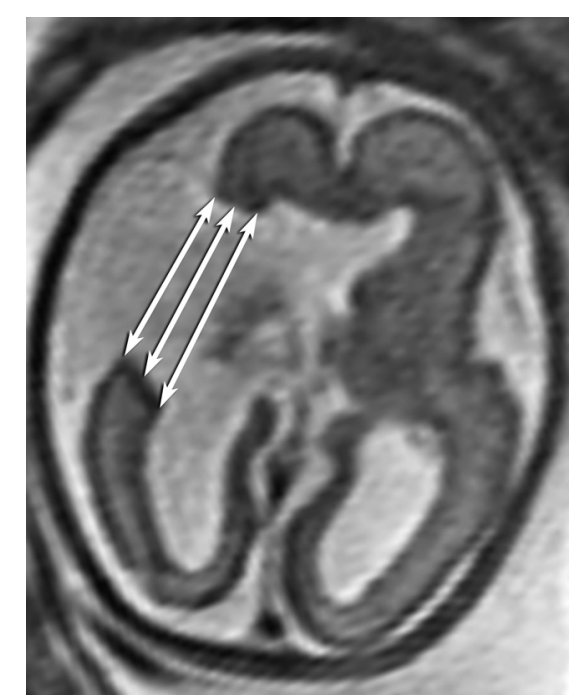

FIG 1. Measurement of the outer, middle, and inner widths of the schizencephalic cleft.

(Siemens). The MR imaging sequences varied among subjects, given the long timeframe in this retrospective study, but included sagittal and axial T1-weighted, axial and coronal T2-weighted, axial and coronal fluid-attenuation inversion recovery, axial diffusion-weighted imaging, and axial $\mathrm{T}^{\star}$ gradient-echo or susceptibility-weighted imaging.

\section{Imaging Review}

All MR imaging studies of these subjects were reviewed by a pediatric neuroradiologist (with 8 years' fetal MR imaging experience) and a second-year neuroradiology fellow (with 1 year of fetal MR imaging experience) and were reported by consensus. For each scan, data on schizencephaly type, number of clefts, location of clefts, status of the cortex lining the defect, the presence or absence of a covering membrane (a thin linear membrane along the surface or depth of the cleft), the presence of signs of hemorrhage, and the presence of other anomalies were recorded. The schizencephalic clefts were considered open if CSF could be tracked through the defect from the lateral ventricle to the subarachnoid spaces. If there was complete apposition of the defect walls at any point or if the defect walls were only separated by intervening vessels in all 3 planes, the clefts were considered closed. Detection of hemorrhage was largely based on the presence of focal hypointensity on T2, hyperintensity on T1, and an excessive susceptibility effect on $\mathrm{T} 2{ }^{\star}$ gradient-echo or susceptibility-weighted images.

Quantitative measurements were made of the width of the schizencephalic cleft (outer, middle, and inner margins) and the width of the ipsilateral ventricle at the level of the atrium to assess a possible relationship between the size of the cleft or ventricle and changes in the appearance of the cleft between the prenatal and postnatal scans (Fig 1). Cleft-width measurements were done either on axial or coronal planes, based on the imaging plane that showed the clefts better for accurate measurement on prenatal imaging. However, they were performed consistently in the same plane between the prenatal and postnatal studies in each subject. In 2 clefts, the outer and midcleft width measurements could not be made because the clefts were large and it was difficult to deter- 
mine the margins. Similarly, 2 ventricular width measurements could not be made because the cleft engulfed the region of the ventricular atrium. To account for the marked differences in head size in the various gestational and postnatal ages, we normalized all the measurements to the mean of the maximum anteroposterior and transverse inner diameters of the skull.

\section{Statistical Analysis}

Paired sample $t$ tests were used to compare the absolute and normalized width of the ipsilateral ventricle and width (outer, middle, and inner) of the cleft between pre- and postnatal imaging. A $\chi^{2}$ test was used to investigate the possible effect of hemorrhage between open defects that remained open and those that had closed on postnatal imaging. $T$ tests were used to compare the prenatal absolute and normalized width of the ipsilateral ventricle at the level of the atrium and the width (outer, middle, and inner) of the defect between open defects that remained open and those that were closed on postnatal imaging.

\section{RESULTS}

Ten subjects with both prenatal and postnatal MR imaging were included in this study. The mean age of the subjects at the time of prenatal imaging was $27.6 \pm 4.1$ weeks (range, $25-35$ weeks). The median age of the subjects at the time of postnatal imaging was 1.5 months (range, 1 day to 7 years) (On-line Table). The reasons for fetal MR imaging referral included sonographic suspicion or diagnosis of ventriculomegaly in 3 (30\%), holoprosencephaly in 3 (30\%), absence of the cavum septum pellucidum in $2(20 \%)$, and detection of a cyst in the brain in $2(20 \%)$, with one of the latter also diagnosed with agenesis of the corpus callosum by sonography. All patients had been referred from outside institutions for fetal MR imaging, so the actual experience of the sonography physician was not known.

Eight (80\%) subjects had bilateral clefts, and $2(20 \%)$ subjects had unilateral clefts, resulting in 18 clefts. Most (15 of 18, 83\%) were open on prenatal MR imaging, but only 8 (53\%) of those remained open on postnatal MR imaging, secondary to closing of the cleft in 7 (47\%) (On-line Table and Figs 2 and 3). Only 3 (16\%) clefts were closed on prenatal MR imaging compared with $10(55 \%)$ on postnatal MR imaging. In all 18 clefts, there was at least partial visualization of the gray matter lining of the 2 margins (lips) of the cleft on prenatal imaging. In 67\%, there was visualization of gray matter completely lining the cleft margins, and in $32 \%$, there was only partial visualization of the gray matter lining a small portion of the cleft margins. A complete gray matter lining was visualized in all 18 clefts on postnatal imaging, confirming the diagnosis of schizencephaly. In schizencephaly, the clefts are anatomically lined with dysmorphic gray matter and polymicrogyria. Dysmorphic gray matter with polymicrogyria was grossly detectable along the cleft in only 3 of 18 (17\%) subjects on prenatal imaging, with the remainder only showing an apparent smooth lining, within the resolution limits of prenatal MR imaging. Polymicrogyria separate from the defect was found in 3 subjects (17\%) postnatally but was only detected in 2 of the $3(66 \%)$ prenatally.

The septum pellucidum was absent in 9 subjects (complete in 8 , partial in 1), and all were detected both prenatally and postnatally. Bilateral subependymal nodular heterotopia was also de- tected in 1 subject on postnatal MR imaging, which appeared to be only unilateral prenatally. Optic nerve hypoplasia was detected postnatally in 3 cases but could not be detected prenatally. A covering membrane was detected in 10 defects prenatally (Fig 4) but only persisted in 2 defects postnatally. Other associated anomalies included agenesis of the corpus callosum and coloboma in the same subject, detected both pre- and postnatally. Some evidence of prior hemorrhage was seen either on prenatal or postnatal imaging in 15 of 18 (83\%) patients (Table 1).

When we compared the normalized pre- and postnatal ventricular and cleft width measurements, the normalized ipsilateral ventricular width $(0.15$ versus $0.12, P=.003)$, inner cleft width (0.14 versus $0.10, P=.038)$, and middle cleft width $(0.15$ versus $0.08, P=.004)$ were all significantly decreased postnatally compared with prenatal normalized widths. However, the normalized outer width of the defect did not significantly change between pre- and postnatal imaging ( 0.19 versus $0.13, P=.09)$. The $\chi^{2}$ test revealed that there was no significant relationship in the prevalence of hemorrhage between open clefts that remained open postnatally and those that had closed on postnatal imaging (either pre- or postnatally detected hemorrhage, $P=.36$; prenatally detected only hemorrhage, $P=.33$; postnatally detected only hemorrhage, $P=.11$ ). Comparing open defects that remained open with those that closed demonstrated that although the outer, inner, and midwidths trended toward being smaller in the latter group, the differences were not statistically significant (Table 2). The normalized prenatal width of the ipsilateral lateral ventricle was also not different between defects that remained open compared with those that had closed (mean normalized width, 0.14 versus $0.16 ; P=.24$; Table 2 ).

\section{DISCUSSION}

The results of this study suggest that most schizencephalic clefts are seen as open-lip defects in the prenatal period, and a large proportion (47\%) will be seen as closed defects when imaged after birth. Most of our subjects demonstrated bilateral defects; this finding is higher than that reported in previous publications. ${ }^{9,10,15,16}$ In previous studies of postnatal imaging of schizencephaly, open defects were the predominant pattern in some, ${ }^{10,15}$ while closed defects were more common in another report. ${ }^{9}$ None of these larger case series studies had serial imaging or had documented open defects converting to closed defects as we have shown in this study. Open defects were consistently the predominant pattern in prenatal imaging of schizencephaly in previous series, ${ }^{3,17}$ which is consistent with our results.

The fine membrane that covers the roof or floor of the defect is likely a remnant of the pia mater or ependyma and is a rarely reported finding in schizencephaly. ${ }^{15}$ In our series, the prevalence of detecting a membrane was much more common prenatally. Part of this may be due to closure of the defect in some cases; however, we had open defects with prenatally documented membranes that remained open after birth but a membrane could no longer be visualized. The reason the membrane is no longer seen postnatally is not clear, but it may be that chronic distention and tension on the membrane leads to its thinning and dissolution. A similar phenomenon is commonly observed in the septum pellucidum in patients with long-standing or severe hydrocephalus. 

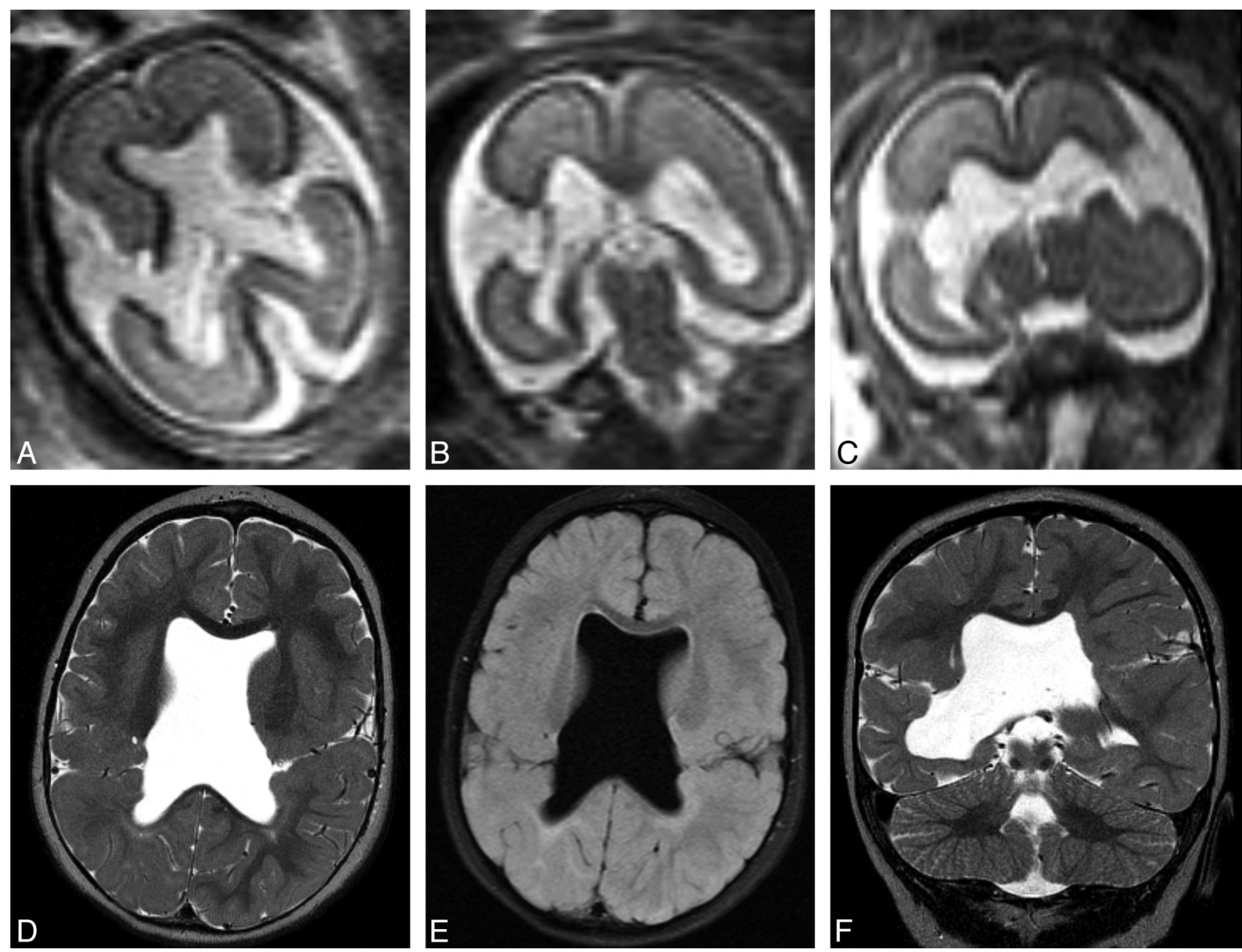

FIG 2. Prenatal imaging at 22 weeks' gestational age demonstrates bilateral wide-open clefts on axial ( $A$ ) and coronal HASTE ( $B$ and $C)$ imaging. Postnatal imaging at 15 months of age demonstrates interval closure of both defects, with apposed lips that contain intervening vessels. Note the complete absence of the septum pellucidum. Axial T2 (D), axial FLAIR ( $D$ and $E$ ), and coronal T2 $(F)$ images are shown.
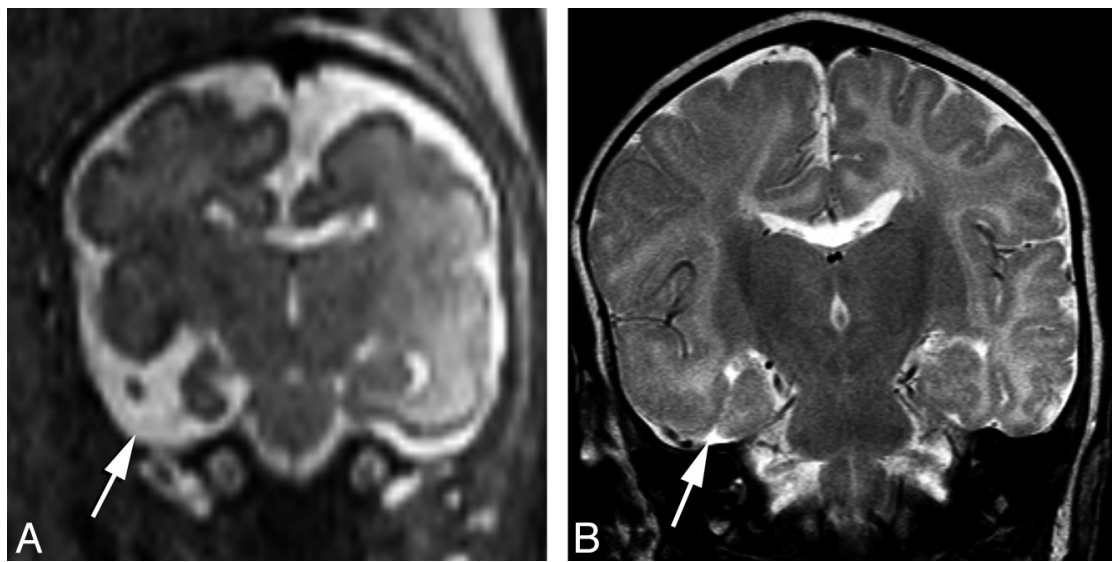

FIG 3. Prenatal coronal HASTE imaging at 26 weeks' gestational age demonstrating a right temporal open cleft communicating with the temporal horn (arrow), with a faint membrane covering (A). Postnatal coronal T2 imaging at 2 months of age demonstrates interval closure of defect lips, which are now apposed to each other and closed $(B)$.

Although visualization of gray matter along the margin of the cleft was much better on postnatal imaging compared with prenatal MR imaging, there was at least partial visualization of gray matter in all cases to suggest the diagnosis of schizencephaly on prenatal MR imaging. A careful inspection for the gray matter lining is required on multiple planes to differentiate it from porencephaly because the gray matter lining may be small and appear incomplete in some cases and, therefore, difficult to identify.

Numerous associated anomalies have been reported with schizencephaly, including polymicrogyria (both adjacent to and remote from the defect $)^{15}$; partial or complete absence of the septum pellucidum $^{3,9,12,18}$; a thinned or absent corpus callosum; and gray matter heterotopia. ${ }^{15}$ Fetal MR imaging did not detect a grossly dysmorphic appearance of the gray matter lining and polymicrogyria along the cleft in most patients. Fetal MR imaging also detected only some of the cases with polymicrogyria outside the defect and detected subependymal nodular heterotopia on only 1 side in a patient with bilateral heterotopia. The presence of optic 
nerve hypoplasia was not identifiable on prenatal imaging in any of the 3 patients with this finding. These limitations are likely due to the resolution limits of fetal MR imaging.

The high number of subjects with absence of the septum pellucidum in our series is consistent with the findings in previous literature. ${ }^{2,18,19}$ The high number of septal defects caused some authors to regard it as part of the definition of or in the same $\operatorname{group}^{18,19}$ as schizencephaly. Raybaud et $\mathrm{al},{ }^{9}$ in a retrospective study of 16 postnatal cases of schizencephaly, demonstrated a correlation between the absence of the septum pellucidum and the frontal location of the defect. We also found the same trend in our

series (On-line Table), with all of our subjects with complete absence of the septum having frontal defects (unilateral or bilateral). We also had 1 case of partial absence of the septum (posterior septal defect) that had parietal and temporal defects, which is also consistent with the findings of Raybaud et al, ${ }^{9}$ who noted a correlation of posterior septal defects with parietal schizencephalic defects. In our study, the absence of the septum pellucidum was detected by prenatal MR imaging in all cases, which was higher compared with the sonography series by Howe et al, ${ }^{20}$ because they only detected the absence of the septum pellucidum in 6 of 8 cases.
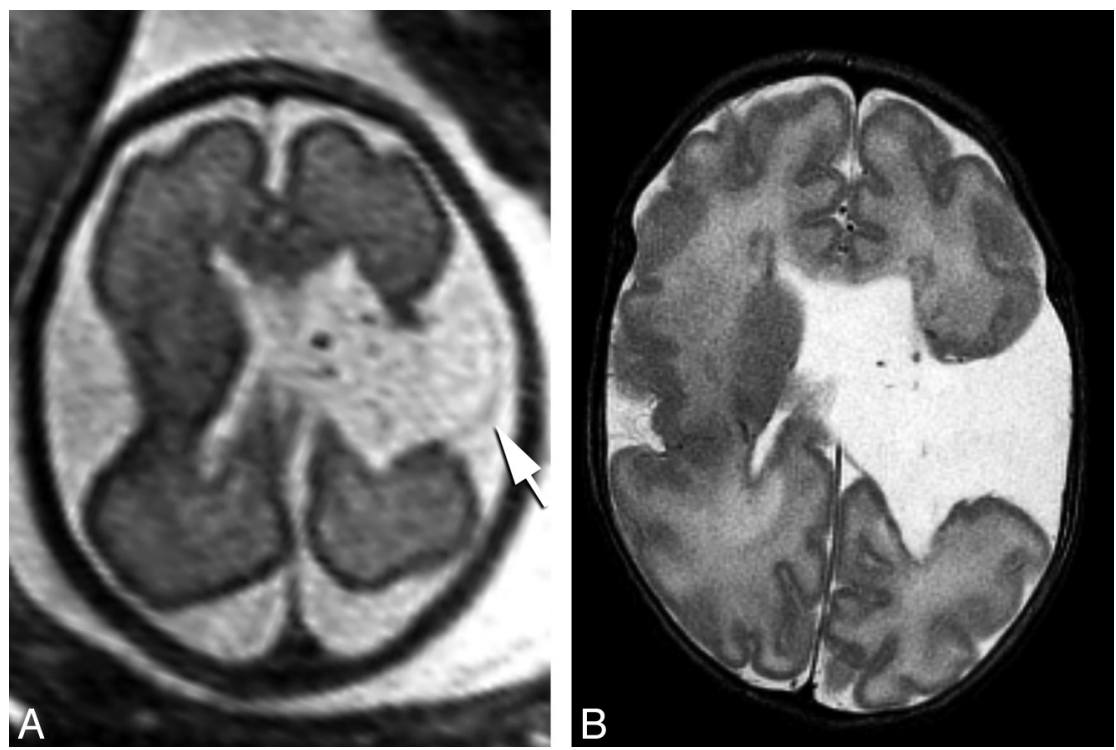

FIG 4. Prenatal imaging at 29 weeks' gestational age. Axial HASTE image $(A)$ reveals an open cleft with a membrane along the roof of the cleft (arrow), which remained open in postnatal imaging 1 month after birth $(B)$.

\section{Table 1: Imaging characteristics of patients with schizencephaly}

\begin{tabular}{|c|c|c|c|c|c|c|c|}
\hline Subject & Clefts & $\begin{array}{l}\text { Prenatal: Visualization of } \\
\text { Cortex Lining the } 2 \\
\text { Margins of the Cleft }\end{array}$ & $\begin{array}{l}\text { Postnatal: Visualization } \\
\text { of Cortex Lining the } \\
2 \text { Margins of } \\
\text { the Cleft }\end{array}$ & $\begin{array}{l}\text { Prenatal: } \\
\text { Membrane along } \\
\text { the Cleft }\end{array}$ & $\begin{array}{l}\text { Postnatal: } \\
\text { Membrane along } \\
\text { the Cleft }\end{array}$ & $\begin{array}{l}\text { Prenatal: Evidence } \\
\text { of Hemorrhage }\end{array}$ & $\begin{array}{l}\text { Postnatal: Evidence } \\
\text { of Hemorrhage }\end{array}$ \\
\hline \multirow[t]{2}{*}{1} & $R$ & Partial-partial & Complete-complete & Present & Absent & $\begin{array}{l}\text { Bilateral ventricular } \\
\text { hemosiderin } \\
\text { staining }\end{array}$ & Absent \\
\hline & $\mathrm{L}$ & Complete-partial & Complete-complete & Absent & Absent & $\begin{array}{l}\text { Right choroid plexus } \\
\text { hemorrhage }\end{array}$ & \\
\hline \multirow[t]{2}{*}{2} & $\mathrm{~L}$ & Complete-partial & Complete-complete & Absent & Absent & Absent & Absent \\
\hline & $\mathrm{L}$ & Complete-complete & Complete-complete & Absent & Absent & & \\
\hline \multirow[t]{2}{*}{3} & $\mathrm{R}$ & Complete-partial & Complete-complete & Present & Absent & Absent & Absent \\
\hline & $\mathrm{L}$ & Complete-complete & Complete-complete & Present & Absent & & \\
\hline \multirow[t]{2}{*}{4} & $\mathrm{R}$ & Complete-partial & Complete-complete & Absent & Absent & Absent & Absent \\
\hline & $\mathrm{L}$ & Complete-partial & Complete-complete & Absent & Absent & & \\
\hline \multirow[t]{2}{*}{5} & $\mathrm{R}$ & Complete-complete & Complete-complete & Present & Absent & $\begin{array}{l}\text { Left lateral ventricle and } \\
\text { choroid plexus gross } \\
\text { hemorrhage }\end{array}$ & $\begin{array}{l}\text { Bilateral ventricular staining, } \\
\text { left choroid plexus } \\
\text { staining }\end{array}$ \\
\hline & $\mathrm{L}$ & Complete-partial & Complete-complete & Present & Absent & & \\
\hline 6 & $\mathrm{~L}$ & Complete-complete & Complete-complete & Absent & Absent & $\begin{array}{l}\text { Hemosiderin staining in } \\
\text { the cleft }\end{array}$ & $\begin{array}{l}\text { Bilateral ventricular and } \\
\text { cleft staining }\end{array}$ \\
\hline \multirow[t]{2}{*}{7} & $\mathrm{R}$ & Complete-partial & Complete-complete & Absent & Absent & Absent & $\begin{array}{l}\text { Left choroid plexus } \\
\text { hemorrhage }\end{array}$ \\
\hline & $\mathrm{L}$ & Complete-partial & Complete-complete & Absent & Absent & & \\
\hline 8 & L & Complete-partial & Complete-complete & Present & Partial & $\begin{array}{l}\text { Bilateral ventricular, choroid } \\
\text { plexus, and cleft } \\
\text { hemosiderin staining }\end{array}$ & $\begin{array}{l}\text { Bilateral ventricular, choroid } \\
\text { plexus, and cleft } \\
\text { hemosiderin staining }\end{array}$ \\
\hline \multirow[t]{2}{*}{9} & $\mathrm{R}$ & Complete-partial & Complete-complete & Present & Absent & $\begin{array}{l}\text { Bilateral ventricular } \\
\text { hemosiderin staining }\end{array}$ & $\begin{array}{l}\text { Bilateral ventricular } \\
\text { hemosiderin staining }\end{array}$ \\
\hline & $\mathrm{L}$ & Complete-partial & Complete-complete & Present & Absent & & \\
\hline \multirow[t]{2}{*}{10} & $\mathrm{R}$ & Complete-complete & Complete-complete & Present & Absent & $\begin{array}{l}\text { Bilateral ventricular } \\
\text { hemosiderin staining }\end{array}$ & $\begin{array}{l}\text { Bilateral ventricular } \\
\text { hemosiderin staining }\end{array}$ \\
\hline & $\mathrm{R}$ & Complete-complete & Complete-complete & Present & Present & & \\
\hline
\end{tabular}

Note:- $\mathrm{R}$ indicates right; $\mathrm{L}$, left. 
Table 2: Comparison of the dimensions of the clefts and ipsilateral ventricle between different types of open clefts ${ }^{a}$

\begin{tabular}{lccc}
\multicolumn{1}{c}{ Measurement } & $\begin{array}{c}\text { Normalized Prenatal Diameters } \\
\text { (Open Clefts That Closed) }\end{array}$ & $\begin{array}{c}\text { Normalized Prenatal Diameters } \\
\text { (Open Clefts That Remained Open) }\end{array}$ & P Value \\
\hline Ipsilateral ventricle & Mean $=0.16 \pm 0.045$ & Mean $=0.14 \pm 0.039$ \\
Cleft width (outer) & Mean $=0.17 \pm 0.14$ & Mean $=0.27 \pm 0.13$ & .24 \\
Cleft width (inner) & Mean $=0.14 \pm 0.88$ & Mean $=0.20 \pm 0.12$ & .11 \\
Cleft width (mid) & Mean $=0.12 \pm 0.08$ & Mean $=0.23 \pm 0.13$ & .14 \\
\hline
\end{tabular}

${ }^{a}$ Measurements are all normalized to the mean of the maximum anteroposterior and transverse inner diameters of the skull.

icant proportion have terminated their pregnancies in previously published studies. ${ }^{17,23}$ Awareness of the fact that open clefts can close may potentially affect prenatal counseling regarding postnatal prognosis.

Prenatal sonography has been used for diagnosis of schizencephaly, ${ }^{3,24}$ though it has been reported that even sizeable open defects may be missed with second-trimester sonography scans ${ }^{24}$ and it is more typically identified during the third-trimester sonography examinations. ${ }^{3}$ Howe et $\mathrm{al}^{20}$ studied 38 cases of schizencephaly by searching collected register data and revealed that only 18 of the 38 cases were identified prenatally. In their study, the main diagnostic technique was sonography, and MR imaging was used in only 6 of the 18 prenatally detected cases. Due to the limitations of sonography, MR imaging is considered the study of choice for the evaluation of suspected schizencephaly. The focus of our study was not a comparison of the accuracy of ultrasound versus MR imaging for the diagnosis of schizencephaly. There are only a few small studies evaluating the prenatal MR imaging of schizencephaly. The largest published series are those of Oh et al $(6 \text { cases })^{3}$ and Denis et al ( 3 cases). ${ }^{17}$ Both of these studies were limited to subjects with open-lip schizencephaly (unilateral or bilateral), and the pregnancy was terminated in all 3 subjects in the study of Denis et al. Recent work by Glenn et $\mathrm{al}^{25}$ on a relatively large series of fetal MR imaging in subjects with malformations of cortical development included 3 subjects with schizencephaly. In their study, fetal MR imaging had 100\% sensitivity and specificity for the prenatal diagnosis of schizencephaly in their 3 patients (both open and closed). We also demonstrated a perfect correlation on the number of defects between pre- and postnatal imaging; however, our methodology was different, having been based on retrospective selection of subjects with schizencephaly. Therefore, the sensitivity of prenatal MR imaging for the diagnosis of schizencephaly cannot be evaluated.

There are 2 single case reports in the literature that described unilateral schizencephaly changing from the open type prenatally to the closed type postnatally. ${ }^{24,26}$ Our study of 18 clefts demonstrated closure of prenatally diagnosed open clefts in $47 \%$ of cases on postnatal imaging. We qualitatively and quantitatively assessed a number of parameters to determine whether we can predict closure of prenatally open clefts. These factors included cleft width at 3 measurement points, ventricular width, and the presence of hemorrhage, but none showed a statistically significant relationship to the closure of open defects. A smaller normalized width of the midportion of the cleft showed a strong trend ( $P=$ $.06)$ in predicting closure of open clefts, but it did not reach statistical significance in our sample. The exact timing of the process of closure of the open schizencephalic clefts is not known. However, we believe that the closing occurs sometime in the later stages of prenatal life because some of our patients who were imaged in early postnatal life still showed closing of the clefts. The cause of closing of open schizencephalic clefts is also not known, but we hypothesize that it may be related to continued growth of the cortical plate or changes in CSF hemodynamics. While we could not statistically relate the closure of clefts to the presence of hemorrhage, the size of the clefts, or the size of the ventricles, future studies with larger numbers may be sufficiently powered to potentially demonstrate an association.

The major limitation of this study is the small sample size, despite being a rather large study of the condition, which is partly due to the rarity of the condition and lack of imaging follow-up, because most of our baseline subject pool was referred from other institutions only for their prenatal assessment. Prospective studies with larger numbers of subjects accompanied by short- and longterm clinical follow-up are needed to investigate the long-term clinical outcome between those subjects whose defects are closed after birth and those whose defects remain open. Larger studies may also elucidate factors that predict closure in a subset of open defects.

\section{CONCLUSIONS}

This study showed that nearly half of open schizencephaly defects seen on fetal imaging will be closed when evaluated on postnatal MR imaging. Prenatal MR imaging can only demonstrate some of the associated anomalies. More precise knowledge of the prenatal and postnatal imaging appearance of schizencephaly and associated anomalies may have important implications in counseling and management of these patients.

Disclosures: Robert A. Zimmerman—UNRELATED: Expert Testimony: various law firms.

\section{REFERENCES}

1. Curry CJ, Lammer EJ, Nelson V, et al. Schizencephaly: heterogeneous etiologies in a population of 4 million California births. $\mathrm{Am} \mathrm{J}$ Med Genet A 2005;137:181-89

2. Barkovich AJ, Raybaud C. Congenital malformations of the brain and skull. In: Barkovich AJ, Raybaud C, eds. Pediatric Neuroimaging. 5th ed. Philadelphia: Lippincott Williams \& Wilkins; 2012:367-568

3. Oh KY, Kennedy AM, Frias AE, et al. Fetal schizencephaly: pre- and postnatal imaging with a review of the clinical manifestations. $R a$ diographics 2005;25:647-57

4. Squier W. Pathology of fetal and neonatal brain damage: identifying the timing. In: Squier W, ed. Acquired Damage to the Developing Brain: Timing and Causation. London, UK: Arnold; 2002:110-28

5. Granata T, Farina L, Faiella A, et al. Familial schizencephaly associated with EMX2 mutation. Neurology 1997;48:1403-06

6. Tietjen I, Bodell A, Apse K, et al. Comprehensive EMX2 genotyping of a large schizencephaly case series. Am J Med Genet A 2007;143A:1313-16

AJNR Am J Neuroradiol 35:1418-24 Jul 2014 www.ajnr.org

1423 
7. Brunelli S, Faiella A, Capra V, et al. Germline mutations in the homeobox gene EMX2 in patients with severe schizencephaly. Nat Genet 1996;12:94-96

8. Robinson RO. Familial schizencephaly. Dev Med Child Neurol 1991;33:1010-12

9. Raybaud C, Girard N, Levrier O, et al. Schizencephaly: correlation between the lobar topography of the cleft(s) and absence of the septum pellucidum. Childs Nerv Syst 2001;17: 217-22

10. Barkovich AJ, Kjos BO. Schizencephaly: correlation of clinical findings with MR characteristics. AJNR Am J Neuroradiol 1992;13:85-94

11. Battaglia G, Granata T. Schizencephaly. In: Barth PG, ed. Disorders of Neuronal Migration. London, UK: Mac Keith Press; 2003:127-34

12. Barkovich AJ, Fram EK, Norman D. Septo-optic dysplasia: MR imaging. Radiology 1989;171:189-92

13. Granata T, Battaglia G, D'Incerti L, et al. Schizencephaly: neuroradiologic and epileptologic findings. Epilepsia 1996;37:1185-93

14. Lituania M, Passamonti U, Cordone MS, et al. Schizencephaly: prenatal diagnosis by computed sonography and magnetic resonance imaging. Prenat Diagn 1989;9:649-55

15. Hayashi N, Tsutsumi Y, Barkovich AJ. Morphological features and associated anomalies of schizencephaly in the clinical population: detailed analysis of MR images. Neuroradiology 2002;44:418-27

16. Denis D, Chateil JF, Brun M, et al. Schizencephaly: clinical and imaging features in 30 infantile cases. Brain Dev 2000;22:475-83

17. Denis D, Maugey-Laulom B, Carles D, et al. Prenatal diagnosis of schizencephaly by fetal magnetic resonance imaging. Fetal Diagn Ther 2001;16:354-59

18. Kuban KC, Teele RL, Wallman J. Septo-optic dysplasiaschizencephaly: radiographic and clinical features. Pediatr Radiol 1989;19:145-50

19. Aicardi J, Goutieres F. The syndrome of absence of the septum pellucidum with porencephalies and other developmental defects. Neuropediatrics 1981;12:319-29

20. Howe DT, Rankin J, Draper ES. Schizencephaly prevalence, prenatal diagnosis and clues to etiology: a register-based study. Ultrasound Obstet Gynecol 2012;39:75-82

21. Guerrini R, Carrozzo R. Epilepsy and genetic malformations of the cerebral cortex. Am J Med Genet 2001;106:160-73

22. Packard AM, Miller VS, Delgado MR. Schizencephaly: correlations of clinical and radiologic features. Neurology 1997;48:1427-34

23. Gedikbasi A, Yildirim G, Saygi S, et al. Prenatal diagnosis of schizencephaly with 2D-3D sonography and MRI. J Clin Ultrasound 2009;37:467-70

24. Lee W, Comstock CH, Kazmierczak C, et al. Prenatal diagnostic challenges and pitfalls for schizencephaly. J Ultrasound Med 2009;28:1379-84

25. Glenn OA, Cuneo AA, Barkovich AJ, et al. Malformations of cortical development: diagnostic accuracy of fetal MR imaging. Radiology 2012;263:843-55

26. Fernández-Mayoralas DM, Fernández-Jaén A, Jiménez-De-la-Peña $\mathrm{M}$, et al. Schizencephaly: pre- and postnatal magnetic resonance imaging. J Child Neurol 2010;25:1020-23 